\title{
247 Against Preposterous Philosophies of Mind
}

[Some] imagine that an idea has to be connected with a brain, or has to inhere in a "soul". This is preposterous: the idea does not belong to the soul; it is the soul that belongs to the idea. The soul does for the idea just what the cellulose does for the Beauty of the rose; that is to say, it affords its opportunity. (EPII: 122, 1902).

The remark is found in the second chapter of Peirce's Minute Logic, "On Science and Natural Classes”. There Peirce explains that his classification of the sciences is not an artificial one, conceived in aprioristic fashion, but a living or natural classification, resembling rather the biologist's classification of species. In this context Peirce brings up the relation between ideas and the soul to counter those who say that we first need to know the workings of the human psyche before we can properly classify the things we claim to know. This is the same objection that Peirce makes against psychologism in logic. Peirce's remark, however, reaches far beyond that of a proper classification of the sciences. It captures a view of the mind that runs counter to the tradition in a most radical way. The remark is not an isolated comment either. For instance, more than three decades earlier Peirce illustrated his view by writing: "just as we say that a body is in motion, and not that motion is in a body we ought to say that we are in thought, and not that thoughts are in us" (W2: 227n).

I particularly like the quotation because it encapsulates a concise frontal attack on the modern conception of the mind as it is shaped by, and after, Descartes - a conception that is still very much alive even today. In fact, it addresses not only the original dualistic interpretation - with its radical separation of mind and body - but also its monistic offspring, such as the mind-brain identity theory. Whether we adhere to a dualistic or a monistic account, the basic notion remains the same: our thoughts are believed to spring from some inner source. Not without cynicism, Peirce observes that though Descartes's idea of a pineal gland is routinely ridiculed, "everybody continues to think of mind in this same general way, as something within this person or that, belonging to him and correlative to the real world" (CP 5.128). This modern conception is further reinforced and intertwined with the modern conception of man as an autonomous individual who enters society by choice and preformed. Our inter-

1 Indiana University-Purdue University Indianapolis, USA. 
action with others does not shape our mind; it merely gives it content. In the short space allotted I will say something about this attack on the modern conception of mind and the inspiring alternative it opens up.

In the quotation, Peirce calls the belief that ideas inhere in a soul preposterous. The Century Dictionary, to which Peirce amply contributed, defines preposterous as "having that last which ought to be first", referring to the word's origin as the combination of præ and posterus, the Latin for "before" and "coming after" (CD: 4697). Though over time the word accrued other meanings, Peirce's ethics of terminology suggests he might stick to the original one. In more recent times, Jacques Barzun has been talking of the fallacy of preposterism. By this he means the fallacy of "seeking to obtain straight off what can only be the fruit of some effort, putting an end before the beginning". ${ }^{2}$ Susan Haack has drawn this fallacy more directly into the moral realm, stating that preposterism causes sham reasoning: One is not genuinely interested in what is true, but begins by expostulating what one wants to be true and then uses inquiry to find one's support for it - and we all know that it is much easier to convince someone of what he already believes than to convince someone of something he does not believe, or has not yet formed an opinion about. ${ }^{3}$ The generally held belief that we have a soul, or mind, is a prime example of something that has been found important enough to invite preposterism. Historically, the reasons why we have ascribed a soul to ourselves have varied greatly. To name but a few, we have brought in the notion of a soul as a plausible explanation for how we think, feel, and put our body in motion; as a way to develop a meaningful theory about life after death; as an anchor for theories that rely on the concept of autonomous moral agents; and as the foundation for an epistemology that sought to ground all knowledge in the knowing individual - Descartes's famous ego cogito. It would not be incorrect to say that typically we start with a notion of the soul that for whatever reason we know has to be true - that is unquestionably true and then proceed to show that reality conforms to it. We know what we are looking for, and thus we find it.

If instead we want to put first things first, where do we begin? Taking Peirce's quotation as our guide, we should first explore these so-called ideas. When we reflect upon our thought, it is ideas that we perceive. Hence, to put the soul, or the mind, or the brain ahead of ideas is preposterous. The ideas come first and the soul, mind, or brain, as an explanation for the presence of these ideas and their interconnections, comes after. A familiar way of talking about ideas is

2 Michael Murray (ed.). 2002. The Jacques Barzun Reader. New York: Harper Collins. 398.

3 Susan Haack. 1997. Science, Scientism, and Anti-Science in the Age of Preposterism. Sceptical Inquirer 21(6). 
Locke's. Locke uses the term to stand for "whatsoever is the Object of the Understanding when a Man thinks". ${ }^{4}$ Peirce is in broad agreement with this (CP 1.285), though he objects that Locke and his fellow empiricists are preposterous about ideas. Their conception of ideas comes already pre-loaded with lots of metaphysics. Instead, Peirce develops what he calls phaneroscopy, which studies not ideas but the phaneron as it immediately presents itself independently of any act of the understanding, including those acts that shaped the empiricists' notion of ideas. With the phaneron Peirce means "the collective total of all that is in any way or in any sense present to the mind, quite regardless of whether it corresponds to any real thing or not" (CP 1.284). Connecting it all back to Peirce's classification of the sciences, phaneroscopy is, for Peirce, the most basic of the positive sciences.

Hence, putting first things first, it is with phaneroscopy that we must begin, not with a Cartesian ego cogito, or with the need for some medium that can satisfy our desire for immortality or onto which to paste our personhood. Making what he takes to be minimal assumptions about the phaneron, and with the help of a branch of mathematics that is virtually presuppositionless (topology), Peirce extracts from the phaneron three categories that are present in anything we can possibly think of: firstness (the pure quality of being what it is, positively, and independently of anything else), secondness (the unmediated opposition of a first to something it is not), and thirdness (a positive relation between two firsts that are second to each other). ${ }^{5}$ Suppose that after a long day of travel the next morning you wake up, slowly, in a strange bed. When in that brief moment between sleep and wakefulness you become dimly aware of a general presence, you are close to experiencing pure firstness. When you subsequently become dimly aware also of yourself as being there, an element of secondness enters as what you first experienced is now second to you. This is close to an experience of pure secondness, as the two are still unrelated. When you subsequently recall the travels of the previous day, thirdness emerges, as a positive relation is being established between you and the room. Here, I think, we see the root of our notion of a soul, or a mind, or a self, etc. as a yet undefined (phaneroscopic) opposition that can be fleshed out at the level of thirdness.

First, though, we need to take a step back and ask how anything can be lifted out of this phaneron to begin with. Peirce finds the answer in normative science. Normative science studies the phaneron insofar as it conforms to certain

4 John Locke, An Essay Concerning Human Understanding, edited by Peter H. Nidditch (Oxford: Clarendon Press, 1975), I.i.8.

5 For a brief account, see Cornelis de Waal, Peirce: A Guide for the Perplexed (London: Bloomsbury, 2013), chapter 3. 
ends. Hence, it says that certain things can be lifted out of the phaneron by exploring motives. As is well known, Peirce divides normative science into esthetics, ethics, and logic. In the esthetic mood we extract from the phaneron something that imparts a positive simple immediate quality of totality (CP 5.132); esthetics aims to identify what is "objectively admirable without any ulterior reason" (CP 1.191). Peirce next distinguishes ethics, which studies the conformity of action to something admirable. Finally, logic studies a particular type of action, called reasoning, in relationship to its end, which is truth, or the correct representation in thought of how things are. Normative science thus allows us to extract from the phaneron ideas, like "the earth revolves around the sun", "there is a ship at the horizon", and "we have a soul", some of which are true and others not.

How does this all relate to our notion of a soul or mind? In the late 1860s, Peirce addresses the issue as follows (W2: 202): Though at birth the child is conscious, he does not yet have what Peirce calls a self. The latter is acquired in the interaction with others and with the environment more generally. Peirce gives the example of a mother who warns her child that the stove is hot. The child whose experience with hot and cold is restricted to what he immediately feels disbelieves what he hears because the stove does not feel hot to him. It is only upon touching the stove that the child discovers that his mother's testimony was a better sign of truth than his own experience. Hence, the child becomes aware of error and ignorance, and in effect he responds to it by positing, not deliberately but as a matter of course, something like a self, mind, or soul, in which those errors and his ignorance can inhere. Our initial notion of the self thus emerges from our experience of opposition - from things being different than we think them to be. In attempting to get a better understanding of this predicament, various questions can be asked. Is this hypothesis of a single self not premature? Why not say that the various experiences of discord lead to a multiplicity of selves? If there is a single self, what constitutes its unity? Can we somehow gain direct access to its innards? How does self relate to consciousness? Is there more to self than an accumulation of error and ignorance - of our idiosyncrasies, of our not fitting in? Etc.

Given how the self enters the scene, the most obvious answer is that we come to know it through a prolonged interaction with it. This is pretty much how we come to know anything. Questions like the unity of the self, or its persistence through time, could also find an answer this way - we come to know it like we come to know the unity or persistence of everything else that enters our experience, whether grapefruits or train stations, namely through our interactions with it. Some have argued that we have an immediate access to the self because we are conscious of it. Peirce, however, sees serious problems 
with identifying our mind or self with our consciousness of it. Though our nervous system happens to exhibit both the phenomenon of consciousness and that of mind, this does not prove them identical, and the discovery of unconscious mind is a clear strike against it (CP 7.364). Peirce sees the relation as follows: When we are conscious of something - for instance, that rose bushes have sharp thorns - this is merely the inward aspect of what is essentially an outward fact. And it would be a mistake to confuse the former for the latter, or to simply assume them equivalent. Peirce argues further that how we are conscious of our own thoughts is not in any essential way different from how we are conscious of common facts, like seeing a tree down the road, hearing a train cross a bridge, or smelling that the toast is burnt.

Peirce's response lies in his semeiotics. We appear to ourselves - as everything appear to us - as a sign, that is, as something that stands for something else in some respect. Every perception, including the products of what is commonly called introspection, is an interpretation of something (i.e., a sign) that is made determinate by something it is not (the object the sign is a sign of). We do seem to have immediate experiences, say, when we experience an unexpected blow against the head, but that is merely a limiting case. What makes it immediate is not some direct insight, but that it is not (yet) determined by something it is not - say the stray baseball that was responsible for it. All meaningful perception is mediated; it is the result of an abduction, conscious or unconscious, in which it appears as a plausible hypothesis - that is, as something worthy of being lifted from the phaneron. This is true also for our experience of self.

It next becomes our task to flesh out this hypothesis, and to do so independently of anything else we want our selves to be. Because space is limited, I can only give the very beginnings of a brief sketch. Since we appear to ourselves as an (admittedly complex) sign, we appear to ourselves as second. The result is a duality that manifests itself as an inner dialogue wherein we constantly chase our own tale without ever catching up: we endlessly replace our self with a new interpretation of our self. The sign that we are to ourselves is thus always a sign external to the new self that is being generated in the interpretation of our old self, and which itself emerges as a sign to be interpreted. Seen this way, there is no essential difference between my being in dialogue with my self (or myself) and my being in dialogue with some other self. The issue is merely one of access. In the dialogue we carry on with our self we have accustomed ourselves to suppressing our vocal cords, thus creating a silent conversation that only we can hear. Moreover, through our memory we have access to information, however dubious at times, that others have not. These differences, however, are inconsequential. There are inaudible dialogues between others as well, 
and there is a great variety of sources of information, all with their own restrictions on who can access them and when.

Our discussion shows that the conversation with one's self is derivative. We are not born talking to ourselves but only acquire this trait by having first conversed with others. Hence, in our exploration we should begin with the communal mind, the mind that we come to partake in after birth, as it is from this that our so-called individual minds, or souls, are subsequently distilled. It is the ideas that shape our self, not our self that shapes our ideas; we learn to speak about ourselves by being spoken to, sometimes with disastrous consequences. Earlier we saw that we begin to attribute a mind, self, or soul, to ourselves (the terms vary) when we come to realize that sometimes there is a discrepancy between what we think and how things are. This consciousness then comes to suggest what belongs to this mind and what does not. We realized, however, that this rests upon us confusing the thought, or the idea, with our being conscious of that thought. This being conscious of the thought is merely its inward aspect - something that accrues to the idea without belonging to its essence. Put in semeiotic terms, albeit not Peirce's, it is part of the sign vehicle without being part of the sign proper. Take a weathervane that signals the direction of the wind. This weathervane has many elements that enable it to act as a sign afford it its opportunity as Peirce has it. These elements, however, are not essential to the weathervane acting as a sign because they could have been very different - the weathervane could have been made of different material, have a different colour, shape, size, etc. Thus, if my thinking that the earth revolves around the sun constitutes a sign (because at that moment this is how I appear to myself), my being conscious of it has the same relationship to the thought as the chicken on a weathervane has to the direction of the wind. It is part of the vehicle that enables that particular sign action to occur without being essential to it. One and the same thought-sign - say that the earth revolves around the sun - an reside in anything that enables it to act as that sign. Though this surely includes individual human consciousness, it is certainly not limited to it. It can be written in a book, carved in stone, painted on canvas, or displayed with a Java app on a website. In fact, Peirce is keen to observe that it makes far more sense to say that an author's thought resides in his books, of which countless copies are printed, than in his brain. In determining its meaning it is not the intention of the author that counts, nor the consciousness that generated or accompanied the thought, but the interpretation by others, including the author's future self, and this is a result of the sign action of the thought on paper. Once the book is printed, the author too becomes a reader.

Now what can we say of the unity of the self or rather, of ourselves, or of its persistence through time? I believe that I am the teenager that played rugby 
1 at eighteen, the journalist that covered the fall of the Berlin Wall in his late 2 twenties, the philosopher that wrote a book on Peirce, etc. One way of stating 3 this is that all those moments belong to one and the same person. If the self is 4 how we appear to ourselves, then we can look at personhood as a consistent 5 thread through a multiplicity of selves - both synchronic and diachronic 6 which together constitute a sign that elicits interpretation. We can even look at 7 the body, with all its changes and transformations, as its sign vehicle. Note, 8 though, that such personhood is not an isolated, internal affair. It is a public 9 affair, even though for much of it I am the only witness; it includes what others necessary that everything that forms a consistent thread through a multiplicity of selves, and would thus be a person, be all connected to a single body or follow a single temporal train. A football team, and even a book or a theory, could be a person. The term might apply even to a bulky report on global warming written perhaps by a hundred experts of whom none has a clear picture of the issue at hand or of all that the text in a broad sense entails. ${ }^{6}$

All of this at best hints at some most rudimentary beginnings of a criticism of the traditional conceptions of consciousness, mind, soul, self, person, etc., with its semeiotic alternative - both suggested by Peirce's writings and inspired by the above quotation.

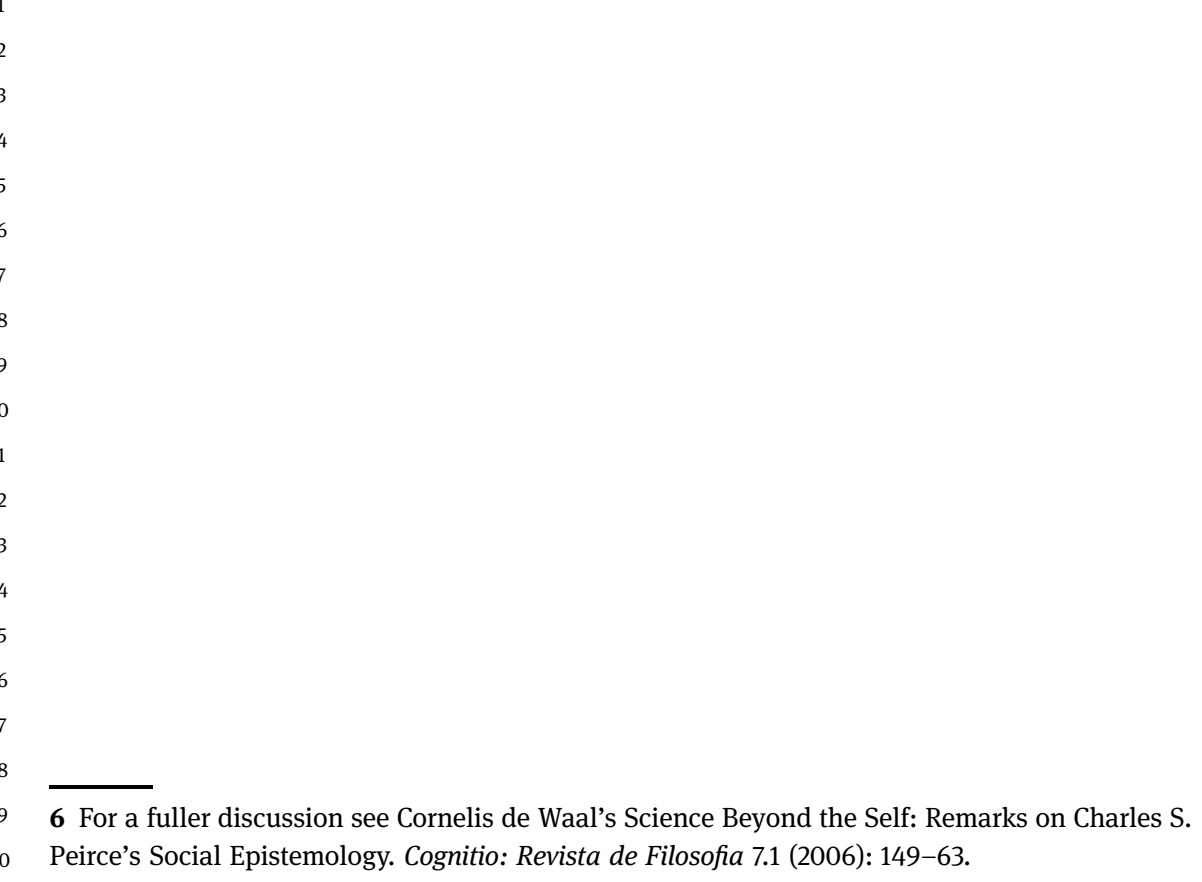

6 For a fuller discussion see Cornelis de Waal's Science Beyond the Self: Remarks on Charles S. Peirce's Social Epistemology. Cognitio: Revista de Filosofia 7.1 (2006): 149-63. 